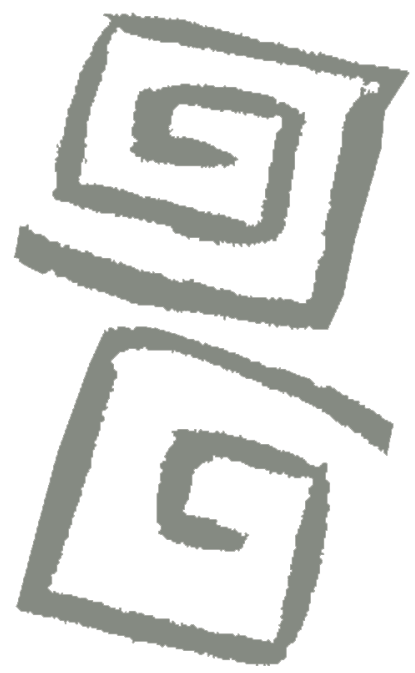

\title{
"Me sentí enfermar": percepciones y comprensión de las mujeres del resultado positivo de un test de virus del papiloma humano en Jujuy, Argentina
}

\author{
"I felt myself getting sick:" women's perceptions \\ and understandings of a positive human \\ papillomavirus test in Jujuy, Argentina
}

Lucila Szwarc ${ }^{1}$, Victoria Sánchez Antelo², Melisa Paolino³, Silvina Arrossi ${ }^{4}$

\begin{abstract}
${ }^{1}$ Autora de correspondencia. Doctora en Ciencias Sociales. Becaria posdoctoral, Centro de Estudios de Estado y Sociedad, Consejo Nacional de Investigaciones Científicas y Técnicas, Ciudad Autónoma de Buenos Aires, Argentina. $\triangle$ (iD)

${ }^{2}$ Doctora en Ciencias Sociales. Investigadora adjunta, Centro de Estudios de Estado y Sociedad, Ciudad Autónoma de Buenos Aires, Argentina. $\triangle$ iD

${ }^{3}$ Doctora en Ciencias Sociales. Investigadora asistente, Centro de Estudios de Estado y Sociedad Consejo Nacional de Investigaciones Científicas y Técnicas, Ciudad Autónoma de Buenos Aires, Argentina. $\triangle$ iD

${ }^{4}$ Doctora en Demografía. Investigadora principal, Centro de Estudios de Estado y Sociedad, Consejo Nacional de Investigaciones Científicas y Técnicas, Ciudad Autónoma de Buenos Aires, Argentina. $\triangle$ (iD)
\end{abstract}

RESUMEN Con el objetivo de analizar las percepciones y clasificar las modalidades de comprensión sobre un resultado positivo del test de virus del papiloma humano $(\mathrm{VPH}+)$, en 2016 realizamos 38 entrevistas en profundidad a mujeres con diagnóstico de VPH + (prueba de Papanicolaou normal y anormal), realizado en el sistema público de salud de Jujuy. Se elaboró una tipología que delimita perfiles de mujeres en función del tipo de comprensión del resultado: 1) comprensión; 2) no-comprensión, a) subestimación, b) sobreestimación, y c) confusión. Entre aquellas que no comprendían, las entrevistadas que confundían el resultado relataron percepciones contradictorias con relación al VPH y su gravedad; quienes lo subestimaban tendían a mencionar ausencia de síntomas y a expresar escasa preocupación; mientras que aquellas que lo sobreestimaban se consideraban enfermas y expresaban preocupación, relato de una ruptura biográfica y dolores físicos. Los hallazgos confirman la necesidad de mejorar los mecanismos de entrega e información sobre los resultados para disminuir el impacto psicosocial en las mujeres y aumentar la adherencia al seguimiento sugerido.

PALABRAS ClAVES Papillomavirus Humano; Servicios Preventivos de Salud; Barreras de Comunicación; Diagnóstico; Cuello del Útero; Argentina.

ABSTRACT With the purpose of analyzing women's perceptions and classifying their modes of understanding a positive human papillomavirus $(\mathrm{HPV}+)$ test, we conducted 38 in-depth interviews with women who had received an HPV diagnosis (normal and abnormal Pap smear), screened in Jujuy's public health system in 2016. A typology based on women's understandings of the result was developed: 1) understanding; 2) lack of understanding; a) underestimation; b) overestimation; c) confusion. The interviewees who experienced confusion over the results reported contradictory perceptions in relation to a positive HPV test and its severity; those who underestimated it tended to mention the absence of symptoms and expressed little concern over the result; while those who overestimated it considered themselves sick and described concern, narrating a biographical disruption and physical pain. These findings confirm the need to improve the delivery of results and the provision of information in order to decrease psychosocial impact and increase follow-up adherence in HPV-positive women.

KEY WORDS Human Papillomavirus; Preventive Health Services; Communication Barriers; Diagnosis; Cervix Uteri; Argentina. 


\section{INTRODUCCIÓN}

Con el objetivo de disminuir la incidencia y la mortalidad por cáncer de cuello de útero, en el año 2012 se implementó la prueba de ADN para el virus del papiloma humano (test de $\mathrm{VPH}$ ) como tamizaje primario en el sistema público de salud de Jujuy, provincia del noreste argentino, con anterioridad a otras provincias del país. El test de VPH permite duplicar la detección de casos con lesiones precancerosas y cáncer, así como facilitar el proceso de prevención ya que se disminuye la cantidad de tamizajes que la mujer debe realizar $^{(1)}$. En el marco de los programas de tamizaje, el cumplimiento del protocolo de seguimiento de las mujeres VPH positivo $(\mathrm{VPH}+)$, con Pap normal o anormal, es fundamental, ya que el tamizaje solo cumple una función preventiva si las mujeres que desarrollaron lesiones de alto grado son tratadas de manera oportuna.

El resultado de un test de $\mathrm{VPH}+$ indica la presencia de un virus asintomático con indicación de seguimiento, que puede desaparecer espontáneamente, permanecer en el cuerpo sin generar ninguna manifestación o bien provocar cambios en las células del

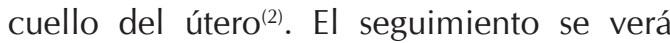
modificado en función de si la persona recibe un resultado de Pap anormal (indicativo de lesiones en el cuello del útero) o de Pap normal (indicativo de ausencia de lesiones). Según los lineamientos de la política sanitaria local, se recomienda repetir el test a los 18 meses, en caso de VPH + con Pap normal, y realizar colposcopía y biopsia, en caso de Pap anormal y, dependiendo del resultado de la biopsia, la mujer podría necesitar un seguimiento de hasta 3 años ${ }^{(2)}$. La necesidad de un seguimiento sostenido en el tiempo, junto con la falta de síntomas y la imposibilidad de tratar y eliminar el virus, hacen que el resultado positivo del test de VPH y/o de un Pap anormal sea una entidad diagnóstica ambigua, de difícil comprensión para las mujeres $^{(3,4,5)}$. La literatura muestra que en algunos casos a las mujeres les cuesta lidiar con la incertidumbre y con la falta de un nombre para su condición, y consideran que la palabra "anormal" en relación a un Pap es poco específica ${ }^{(3)}$. Un estudio llevado a cabo en Suecia encuentra que mujeres que reciben un resultado de Pap anormal consideran que "tienen algo" y ponen en cuestión las palabras utilizadas por los profesionales que les indican, con respecto a las células anormales, que "no tienen nada", lo cual entienden como una indefinición ${ }^{(4)}$. Algunos/as autores consideran que un resultado anormal de Pap es un estado liminal en el pasaje salud-enfermedad, dado que las mujeres no están ni enfermas ni sanas ${ }^{(4,6)}$. Para Forss et al., un resultado anormal de Pap lleva a las mujeres a pasar de una confirmación de rutina sobre su salud a un estado ambivalente o liminal, en tanto no se confirma la salud pero tampoco se descarta la enfermedad. La liminalidad fue definida inicialmente por el antropólogo Van Gennep en relación con ritos de pasaje. Según él, las condiciones o personas liminales no pueden ser definidas en términos estáticos y escapan a las clasificaciones habituales de la estructura social, caen en los intersticios de esta y siempre son ambivalentes ${ }^{(4)}$. Además de los estudios clásicos sobre Pap anormal, es posible considerar que en los casos de mujeres que reciben un Pap anormal con posterioridad o junto con un VPH positivo, esta ambigüedad se acreciente, debido a las características del resultado del test descriptas. Lo mismo se puede sostener con relación a un test de $\mathrm{VPH}+$ y/o de un Pap normal, ya que la indefinición y liminalidad es, de manera inherente, igual o mayor a la de un Pap anormal, dado que la mujer tiene una infección con un virus de alto riesgo oncogénico pero no tiene una entidad diagnóstica que pueda ser tratada.

Las características descriptas hacen que la recepción de un resultado positivo de test de VPH (Pap normal o anormal) pueda tener un impacto psicosocial negativo que moviliza sentimientos de estrés, ansiedad y angustia en las mujeres ${ }^{(7,8,9)}$. Los sentimientos se relacionan con percepciones sociales que asocian el VPH a un cáncer (con ideas fatalistas sobre su prevención) y dependen de la información y de su comprensión ${ }^{(3,10,11)}$. A su vez, el hecho 
de que el VPH sea una infección de transmisión sexual también moviliza sentimientos negativos ligados a la vergüenza y el estigma asociados a este tipo de virus ${ }^{(7,12,13)}$. Si bien existen diversos estudios sobre los significados sociales del VPH y el cáncer ${ }^{(14,15)}$, y sobre los impactos subjetivos de los procesos de entrega de resultados de test de VPH y Pap $^{(16,17,18)}$, la mayoría de estos se centran en la toma de Pap, dejando por fuera las percepciones relacionadas específicamente con el VPH. Además, estos estudios no han analizado en profundidad los modos en que las mujeres comprenden el resultado.

En este contexto, nos propusimos analizar las percepciones que las mujeres otorgan a un resultado positivo de test de VPH, y los posibles resultados posteriores, y clasificar las modalidades de comprensión. El objetivo fue parte de la investigación "Entrega de resultados de un test de $\mathrm{VPH}+\mathrm{y}$ posterior proceso de seguimiento y tratamiento: las experiencias de las mujeres y la mirada de los profesionales en la provincia de Jujuy". Los resultados presentados permitirán elaborar materiales educativos y de comunicación sensibles a las percepciones de las mujeres argentinas y latinoamericanas, y mejorar así sus experiencias de diagnóstico, seguimiento $\mathrm{y}$ tratamiento ante un test de $\mathrm{VPH}+$.

\section{METODOLOGÍA}

Se siguió un enfoque metodológico cualitativo que privilegia el abordaje interpretativo de los procesos sociales y permite la comprensión de las vivencias de salud a partir de las concepciones culturales y simbólicas de los individuos y comunidades ${ }^{(19)}$. Para esto, se analizaron las percepciones de las mujeres sobre un resultado positivo del test de VPH y los posibles resultados posteriores. El estudio formó parte de una investigación más amplia centrada en las perspectivas de las mujeres sobre el proceso de entrega de resultados y adherencia al seguimiento en la prevención del cáncer de cuello de útero. Este enfoque metodológico contribuye a complementar los resultados de estudios cuantitativos, clínicos y epidemiológicos sobre el proceso de prevención del cáncer de cuello de útero.

Se llevaron a cabo entrevistas en profundidad a mujeres $\mathrm{VPH}+$ que se realizaron el test de VPH en el sistema público de salud de la provincia de Jujuy, en el año 2013. El trabajo de campo se realizó durante el mes de junio de 2016. Agentes sanitarios y responsables de atención primaria de la salud provinciales invitaron a las mujeres a participar, con una breve explicación de los objetivos de la entrevista y el estudio. En caso de aceptar, las mujeres fueron contactadas por una entrevistadora, formada en ciencias sociales, para realizar una entrevista individual cara a cara.

El objetivo de la guía de entrevista fue indagar acerca de las percepciones de las mujeres sobre los distintos momentos del proceso de atención-cuidado, a partir de la toma del test de VPH. Así, la guía de entrevista contó con nueve dimensiones: 1) datos sociodemográficos; 2$)$ conocimientos acerca del test de VPH y Pap; 3) realización del test de $\mathrm{VPH}$; 4) entrega de resultados; 5) percepción del resultado; 6) colposcopía/biopsia; 7) resultado de la biopsia; 8) tratamiento; y 9) mirada retrospectiva del proceso de atención y de la relación con profesionales de la salud. Presentamos aquí algunos resultados de las dimensiones 1, 5 y 9 .

Se realizaron 38 entrevistas a mujeres $\mathrm{VPH}+$ de entre 33 y 68 años, con un promedio de 49 años, a la fecha de realización de las entrevistas, de las cuales 26 vivían en zonas urbanas, mientras que 12 residían en áreas rurales. La muestra se distribuyó en 18 mujeres con Pap normal y 20 con Pap anormal. Entre estas últimas, ocho entrevistadas tenían lesiones de bajo grado (BG) y 12 de alto grado (AG). Todas ellas eran mujeres cis (identificadas con el género asignado al nacer) y no refirieron otra identidad de género.

Una gran parte, 22 entrevistas, se realizaron en los domicilios de las mujeres y 4 en sus lugares de trabajo. Algunas mujeres prefirieron realizar la entrevista en algún espacio exterior a su domicilio, como veredas o bancos de plazas (8), un café (1), o un consultorio en un centro de salud (3). La mayoría de las entrevistas se llevaron a cabo en privacidad, 
pero algunas mujeres estaban a cargo de bebés o de niñas o niños de poca edad. En una ocasión, el marido de una entrevistada se encontraba en el domicilio mientras realizábamos la entrevista, e interrumpió dos veces el relato de la mujer, al ingresar en la habitación en la que nos encontrábamos. En otra situación, una mujer que atendía un almacén familiar accedió a participar del estudio si continuaba con su trabajo, por lo que la entrevista se vio interrumpida en dos ocasiones por la presencia de clientes. Las entrevistas duraron 45 minutos en promedio.

Los datos fueron analizados siguiendo los principios de la teoría fundamentada, asumiendo que la teoría emerge en la interacción entre el investigador, la teoría y los datos ${ }^{(20)}$. De acuerdo a esta perspectiva teórico-metodológica, se elaboró una tipología producida, que emergió de los datos y nos permitió describir el fenómeno de (no) comprensión del resultado, delimitando perfiles de mujeres en función del tipo de (no) comprensión y de las características de cada grupo de entrevistadas.

Al hablar de la percepción sobre el resultado recibido hacemos alusión tanto al $\mathrm{VPH}+$ como a los resultados posteriores (de Pap y posible biopsia). Las mujeres entrevistadas podían tener resultados $\mathrm{VPH}+$ con Pap normal, o VPH + con Pap anormal. En este último caso, según el resultado del Pap y una posible biopsia, se identifican lesiones de bajo o alto grado. Se consideran lesiones de bajo grado las atypical squamous cells of undetermined significance o (ASC-US) o células escamosas atípicas de importancia no determinada y las low-grade squamous intraepithelial lesion (LSIL) o lesión escamosa intraepitelial de grado bajo. Respecto a las lesiones de alto grado, se consideran los diagnósticos de atypical squamous cells (ASC-H) o células escamosas atípicas, en las cuales no se puede excluir una lesión de alto grado, o las high-grade squamous intraepithelial lesions (HSIL) o lesión intraepitelial escamosa de alto grado o más ${ }^{(2)}$. De este modo, la muestra incluye mujeres: $\mathrm{VPH}+$ sin sospecha de lesión (Pap normal), VPH + con sospecha de lesión de bajo grado, alto grado o superior (Pap anormal). Si bien podría considerarse que hay diferencias importantes entre estos grupos de mujeres, en todos los casos el diagnóstico implica un resultado positivo del test de VPH con una indefinición inherente, incluso aquellos en los que la biopsia confirma la necesidad de un tratamiento. Aun en estos casos, se trata de un diagnóstico que comienza con la entrega de un $\mathrm{VPH}+$ y cuyo tratamiento no necesariamente resulta en la eliminación del virus y que, además, exige controles posteriores que se podrían extender en el tiempo. A lo largo del análisis, describimos para cada grupo si se trata de mujeres con o sin lesiones en el cuello del útero, y de qué tipo de lesiones se trata.

Todas las entrevistadas dieron su consentimiento para grabar la entrevista y para la utilización de los datos surgidos. Para garantizar el anonimato y la confidencialidad, se utilizaron seudónimos para registrar y transcribir las entrevistas. El protocolo del estudio fue aprobado por el Comité Provincial de Bioética de Jujuy.

A continuación, presentamos los resultados del estudio a partir de una tipología de cuatro perfiles de mujeres, en función de los modos de comprender el resultado. En cada caso, exponemos las percepciones sobre el resultado, sobre sus cuerpos y sobre la forma de transmisión del virus. Además de indicar la edad de la mujer al momento de la entrevista, en cada verbatim utilizamos un nombre ficticio, y señalamos si se trata de mujeres con diagnóstico VPH positivo con o sin lesión en el cuello del útero, y qué tipo de lesión.

\section{RESULTADOS}

\section{Tipología}

Se elaboraron las categorías de comprensión y no comprensión del resultado recibido (VPH + y posibles resultados posteriores). Se consideró que las mujeres "comprenden" el resultado si podían dar cuenta, en alguna medida, de su ambigüedad inherente. Por ambigüedad inherente nos referimos a que un resultado de $\mathrm{VPH}+$ no es sinónimo de un diagnóstico de cáncer, sino que remite a 
un nivel de riesgo oncogénico, donde la enfermedad no se confirma, pero tampoco se puede descartar. La positividad requiere de estudios posteriores para confirmar si hay una lesión, pero no es posible tratar el virus. Incluso si el follow-up posterior (por ejemplo, Pap de triaje) indica normalidad, no significa que el proceso haya culminado, sino que puede implicar la necesidad de seguimiento. En aquellas mujeres con test de VPH positivo persistente al año, se recomienda realizar lectura de la citología, colposcopia y biopsia de imágenes anormales, y luego evaluar el seguimiento de acuerdo al diagnóstico histológico ${ }^{(2)}$. Esta necesidad de controles médicos a lo largo del tiempo podría generar la percepción de una amenaza latente, que no se termina de ir. Se mantiene entonces un estado de indefinición, incertidumbre y liminalidad que, como vimos, puede traer aparejada una percepción de confusión y de no estar "ni acá ni ahí"(4,6) Tenemos en cuenta los puntos equiparables de los resultados recibidos por las mujeres, así como sus diferencias, marcando las diferentes percepciones según sus diagnósticos y tipos de lesiones, cuando corresponda.

El término "comprensión" fue tomado de investigaciones que indican que las mujeres que reciben un resultado positivo de test de VPH y/o Pap expresan confusión sobre la información recibida, debido a la no comprensión de su ambigüedad ${ }^{(3,16,21)}$. A partir de las sucesivas codificaciones, se construyó una tipología de mujeres basada en los criterios de comprensión y no comprensión y, dentro de esta última categoría, se elaboraron subcategorías relacionadas con las diferentes percepciones de gravedad. El término "percepción de gravedad" refiere al grado de consecuencias sociales, personales y médicas negativas que una persona le atribuye a un diagnóstico determinado ${ }^{(22,23)}$. En nuestro análisis, se consideró que las mujeres "comprenden" el resultado si tienen una comprensión general y una percepción de gravedad adecuada, aunque puedan expresar dudas o confusiones. Las mujeres "sobreestiman" el resultado si le asignan un nivel de gravedad excesivo, entendiendo que ya tienen una enfermedad grave o que están enfermas de cáncer. Se
Tabla 1. Tipología de mujeres VPH+ (Pap normal y anormal), testeadas en el sistema público, según comprensión del resultado. Provincia de Jujuy, Argentina, 2013.

\begin{tabular}{|l|l|l|}
\hline $\begin{array}{l}\text { Comprende } \\
\text { No comprende }\end{array}$ & $\begin{array}{l}\text { Da cuenta de la ambigüedad del resultado, en } \\
\text { aspectos tales como el carácter preventivo del test } \\
\text { de VPH, la posible regresión o manifestación en el } \\
\text { tiempo del virus y/o la necesidad de seguimiento en el } \\
\text { sistema de salud, aunque exprese dudas. }\end{array}$ \\
\hline Subestima & $\begin{array}{l}\text { No da cuenta o desconfía de la } \\
\text { necesidad de seguimiento y/o del } \\
\text { propio resultado. }\end{array}$ \\
\hline Confunde & $\begin{array}{l}\text { No puede responder qué significa el } \\
\text { resultado y expone interpretaciones } \\
\text { contradictorias sobre su gravedad. }\end{array}$ \\
\hline Sobrestima & $\begin{array}{l}\text { Le asigna al resultado un nivel de } \\
\text { gravedad excesivo, generalmente } \\
\text { asociado a una enfermedad actual } \\
\text { grave. }\end{array}$ \\
\hline
\end{tabular}

Fuente: Elaboración propia a partir de entrevistas en profundidad.

estimó que las entrevistadas "subestiman" el resultado si cuestionan la presencia del virus y la necesidad de seguimiento. Por último, se consideró que las mujeres "confunden" el resultado cuando no pudieron reponer qué significa y expusieron interpretaciones contradictorias sobre su gravedad. La Tabla 1 resume los dos tipos de comprensión y los tres subtipos de no comprensión.

\section{Tipo 1. Comprensión del resultado}

El grupo de mujeres que comprende la ambigüedad del resultado está conformado tanto por mujeres VPH positivo y Pap normal, como por mujeres con Pap indicativo de presencia de lesiones de bajo y alto grado.

En nuestro corpus, es poco frecuente que las mujeres comprendan el resultado. Cuando lo hacen, utilizan expresiones ligadas a una escala temporal y a un vocabulario de prevención. Sin embargo, en este grupo también encontramos importantes dudas sobre el diagnóstico.

...por precaución, por el tema de mi madre porque puede ser hereditario [...]. Cuando me dio positivo me dijo "son unas células que son cancerígenas... pero no es que tenés cáncer, sino que proba- 
blemente llegues. (Ana, 34 años, VPH+, con lesión BG).

EI PAP me dio negativo y el otro positivo. Me hizo la colposcopía y me dijo que estaba bien, me explicó que está una línea ahí como que yo estoy acá. No estoy ni acá que puede ser malo ni acá que puede ser bueno, que estoy ahí. (Fernanda, 52 años, VPH+, con lesión BG).

Las entrevistadas que comprenden el aspecto preventivo del test de VPH sin omitir el resultado positivo utilizan un vocabulario específico (como "células") y distinguen entre diversos estudios (test de VPH, Pap, colposcopía). También mencionan que se puede "evitar", "cuidar" y que "todas tenemos esto".

Sin embargo, las mismas entrevistadas expresan dudas y confusiones relacionadas, sobre todo, con la transmisión y evolución del virus, con una idea de progresión hacia el cáncer muy marcada.

¿Y le quedaron dudas?

Sí, un poco de duda sí porque las dos veces que fui me dijo que estaba ahí nada más. [No sé] si es posible que se pueda ir para acá, para el peor lado. En qué tiempo se puede ir o si puede desaparecer. (Fernanda, 52 años, VPH+, con lesión BG).

\section{Tipo 2. No comprensión del resultado: subestimación}

Las entrevistadas incluidas en la categoría "subestimación" no dan cuenta de la ambigüedad del resultado recibido (VPH + y posibles resultados posteriores). Las mujeres que subestiman el resultado son, de manera preponderante, aquellas con un resultado positivo del test de VPH, pero con un resultado normal de Pap. En este sentido, la "subestimación" del diagnóstico se podría relativizar, dado que se trata de un virus altamente prevalente con posibilidad de regresión, cuya indicación para el seguimiento es repetir el test luego de un año y medio ${ }^{(2)}$. Sin embargo, dentro de este grupo encontramos que se cuestiona la presencia del virus, su significado y la indicación médica de seguimiento, por lo que consideramos que se "subestima" el resultado.

Algunas de las entrevistadas que subestiman el resultado no recuerdan haberse realizado el test, lo confunden con el Pap u otros estudios, aunque presentan una mirada de prevención relacionada con "controles" o consultas médicas. Es más recurrente, sin embargo, cierta desconfianza hacia las intervenciones y tratamientos por parte del sistema de salud. Al ser consultadas sobre el test de $\mathrm{VPH}$, quienes subestiman el resultado desconfían del diagnóstico o de las sugerencias de seguimiento, debido a la falta de síntomas, al hecho de que las generaciones previas no se realizaron estudios y no se enfermaron, a cierto malestar hacia el sistema de salud (por motivos de maltrato, dolor, sensación de "perder el tiempo", entre otros aspectos) y a diversas creencias en torno a las intervenciones ginecológicas y el cáncer.

¿Y del test de VPH escuchaste hablar?

No. No sé nada la verdad.

¿Y el Pap?

Y el Pap me lo hice, pero no le di bola.

Hace como 4 años me parece, pero nunca fui a buscar resultado, nunca nada. No le tengo fe. [...] Tampoco es culpa de los trabajadores. También soy yo la que nunca se acercó, y siempre me estoy mudando. [...] Como que yo siento que siempre te retan. (Paula, 36 años, $\mathrm{VPH}+$, con lesión BG).

Me dijeron qué tenía que hacer... pero yo no pude ir, porque mirá si ahícito, $y$ te agrava a veces. [...]. No me siento mal. No siento nada de esas molestias ni nada. [...] Mi mami hasta los 82 vivió pero no se ha hecho operar nada. (Olga, 64 años, VPH+, con lesión BG).

Las mujeres que subestiman el resultado describen que debían "repetir el estudio" sin dar cuenta del motivo o hablan de "manchitas" o "bacterias". Si bien no suelen expresar sentimientos relacionados con la recepción del diagnóstico, exponen, como indican los 
testimonios, cierto malestar hacia el sistema de salud en su conjunto.

\section{Tipo 3. No comprensión del resultado: confusión}

Las mujeres entrevistadas también pueden expresar confusión sobre el significado y las connotaciones del resultado, es decir, que no lo sub o sobreestiman, sino que no logran dar cuenta de su significado, plantean dudas fundamentales y/o realizan descripciones contradictorias sobre la gravedad.

No sé exactamente qué es porque nadie me pudo explicar bien. Algo así me dijeron, pero no te sabría explicar cómo es. [...] Después era por el tema que tenía no sé qué cosa... Y después me operaron. Me sacaron... Me hicieron un... no sé cuánto. (Patricia, 41 años, VPH+, con lesión AG).

Los sentimientos que expresan estas mujeres se relacionan con una interpretación del diagnóstico que va desde "manchitas" o "quistecito" hasta "cáncer" o "algo grave". Es habitual que relaten sentimientos contradictorios o de confusión, expongan temor o preocupación por el diagnóstico, pero también vergüenza o incomodidad a la hora de realizar preguntas al personal de salud. Dentro de este grupo de entrevistadas, hay quienes tienen diagnóstico de VPH + con Pap normal, pero también quienes presentan lesiones de bajo y de alto grado.

\section{Tipo 4. No comprensión del resultado: sobrestimación}

Con respecto a la sobreestimación, es importante destacar que se trata -en su mayoría, pero no exclusivamente- de mujeres con Pap anormal, indicativo, sobre todo, de lesiones de alto grado. Si bien las entrevistadas con este tipo de lesiones pueden comprender, subestimar o confundir el significado del diagnóstico, quienes lo sobrestiman suelen interpretar mayor gravedad a partir de un diagnóstico y experiencias de prevención que exceden un diagnóstico específico de $\mathrm{VPH}+$ y se relacionan con la biopsia, su resultado y un posible tratamiento. Consideramos que las mujeres "sobreestiman" el resultado también a la luz de los posibles resultados posteriores, dado que una lesión de alto grado, particularmente en los casos en los que fue tratada, implica la realización de un seguimiento, por el cual se evita una enfermedad. Aún así, en este grupo de mujeres, el significado de los resultados se interpreta como "cáncer" y "enfermedad" y se habla de "peligro" y hasta de "muerte".

...No sé por qué me suceden esos dolores. [...] Por ahí parece que es psicológico porque una vez escuché en la tele diciendo que hay muchas mujeres que mueren con cáncer al útero, no... al cueIlo del útero, ¿puede ser? Y es como que me entró eso en la cabeza. Me duele psicológicamente. [...] Me duele y pienso que es un cáncer y por ahí tengo miedo. A mí por ahí me dan unas puntaditas ahí y me hace todo doler la pierna. Ay, yo no sé, [...] no sé qué será. (Blanca, 34 años, VPH+, con lesión AG).

Las mujeres que sobreestiman el resultado expresan sentimientos de miedo y preocupación relacionados a percibirse enfermas. En sus relatos, encontramos expresiones como "mi enfermedad" o "lo que yo tengo" que se vinculan con una inquietud frecuente que les impide dormir y genera preocupación por su futuro y el de sus hijas e hijos. Algunos de estos testimonios se pueden relacionar con otros estudios sobre las experiencias de pacientes y enfermos, en las que la entrega de un diagnóstico representa un momento de "ruptura biográfica" en la vida de las personas $^{(24,25,26)}$. Como expresan los testimonios, este grupo de mujeres puede percibir cambios físicos, a partir de la recepción del resultado positivo, relacionados con el miedo y la preocupación que, según ellas, también se expresan en sus cuerpos.

Entre las mujeres que sobreestiman el resultado recibido $(\mathrm{VPH}+$ y posibles resultados posteriores), es habitual que las percepciones 
de una "ruptura biográfica" se relacionen a la percepción de gravedad, pero también a la forma de transmisión del virus. Además de la preocupación por percibirse enfermas, se relatan inquietudes ligadas a lo que las mujeres configuran como infidelidad y el impacto de esta noticia sobre sus relaciones de pareja o vinculares. La información sobre la transmisión sexual se relaciona con una gravedad mayor, y se confunden ambos aspectos del virus:

...sola empecé a investigar qué es lo que era, y me di cuenta que era de transmisión sexual. [...] Me sentí re mal. Con mi marido tuve... hasta ahora me duele, porque vos pensás en muchas cosas, [...] y te duele porque [...] te das cuenta de lo que es realmente, te das cuenta lo grave que es. [...] no Ilegaron mis análisis de Jujuy [...] y es como un fantasma que siempre te persigue. (Victoria, 43 años, $\mathrm{VPH}+$, con lesión AG).

\section{Resultados transversales}

La forma de transmisión del virus es un tema de relevancia para el conjunto de las entrevistadas, más allá de su percepción sobre el significado del diagnóstico. En muchas de ellas, esta noticia tiene un impacto en sus relaciones de pareja y se vincula con percepciones tradicionales sobre masculinidad y femineidad, en donde se sostiene que las mujeres tienen una pareja sexual a lo largo de su vida mientras que los hombres tienen "sus aventuras" (entrevista a Vanina). A pesar de esta mirada naturalizadora, las entrevistadas le otorgan gran importancia a la noticia de la vía de transmisión. Se relata miedo a tener relaciones sexuales, la decisión de no volver a hacerlo y situaciones de pareja que van desde conversaciones al respecto hasta discusiones y separaciones.

Te soy sincera: nunca más. De ahí decidí directamente no querer saber más nada de nada. Ni darle bola a mi novio, estoy sola. No quiero ya someterme a todas estas cosas. Porque para mí ya no va.
¿Te separaste después por esto?

Sí, yo sí. Soy una persona que me gusta la sinceridad, ante todo.

¿Pero tampoco quisiste tener más relaciones sexuales?

No, me da miedo. (María Alicia, 44 años, $\mathrm{VPH}+$, con lesión AG).

La dimensión de la transmisión sexual del VPH se juega para las mujeres en una pregunta sobre el momento de haberlo adquirido, pero también, en percepciones sobre sí mismas relacionadas con la vergüenza y el estigma. Podemos decir que hay un "estigma interno" en tanto las entrevistadas se consideran poseedoras de un atributo desacreditador $^{(17)}$. Las mujeres ocultan el resultado por temor al rechazo, sienten vergüenza y describen y justifican situaciones de discriminación relacionadas con el resultado:

\footnotetext{
...tengo una hermana que es muy discriminativa. Por ejemplo, con mi hija una vez fuimos a la casa y estaba resfriada. Ella empieza a quemar algodones, alcohol. Pasa el aerosol y no respeta. O por ahí le digo "tengo anginas". "No vengas así". Si yo le digo eso, no me va a dejar entrar en el baño. (Rosa, 49 años, $\mathrm{VPH}+$, con lesión BG).
}

No van a divulgar mis datos, ¿no? Porque yo vi una película que una mujer tenía ese problema y la gente le rehuía. (Elizabeth, 51 años, VPH+, sin lesión).

Estos aspectos se expresan en los distintos grupos de mujeres sin marcadas diferencias. Solo en el grupo de aquellas que subestiman, algunas entrevistadas no prestan especial atención a la transmisión sexual del virus, dado que minimizan el propio diagnóstico.

Otro aspecto de la percepción del resultado de un test de VPH tiene que ver con la mirada de las mujeres sobre sus cuerpos, a partir de la recepción del diagnóstico. Como vimos, es habitual que las mujeres que subestiman el resultado describan no tener síntomas, mientras que aquellas que lo sobrestiman mencionan cambios y dolores físicos. A su vez, es 
recurrente que las mujeres que presentan confusión en torno al resultado, indiquen falta de síntomas, pero asocien otros síntomas ginecológicos con el diagnóstico recibido, buscando indicios para comprender su condición.

\section{¿Y ahora por qué te acordaste que tenías que hacértelo? \\ Sentía como que me bajaba así mucho coágulo, después del período. Así que he venido a hablar con el médico. Me decía que yo tenía, así como hongos. Y yo le preguntaba si era necesario hacerme de nuevo. (Cecilia, 33 años, VPH+, sin lesión).}

Con excepción de las mujeres que subestiman el resultado, encontramos que en los otros grupos de mujeres cambia la percepción sobre sus cuerpos a partir de la recepción del resultado.

\section{DISCUSIÓN}

Un aporte específico de nuestra investigación es la construcción de una tipología que relaciona las percepciones de las mujeres con la comprensión del resultado. Las entrevistadas que confunden el resultado relatan percepciones contradictorias con relación al VPH+ y su gravedad; quienes lo subestiman tienden a mencionar la ausencia de síntomas y a expresar escasa preocupación al respecto; mientras que aquellas que lo sobreestiman se consideran enfermas $y$, por lo tanto, describen percepciones relacionadas con esta lectura, como preocupación, relato de una ruptura biográfica y dolores físicos. La interpretación del diagnóstico recibido y la falta de comprensión de su ambigüedad se relacionan entonces con las percepciones que expresa cada grupo de mujeres. Estos resultados coinciden con investigaciones que indican que las percepciones y los sentimientos negativos en mujeres $\mathrm{VPH}+\mathrm{y} / \mathrm{o}$ con diagnóstico de Pap anormal se asocian a falta de información ${ }^{(3,10,11)} \mathrm{o}$ a interacciones escasas o insuficientes con los y las profesionales de la $\operatorname{salud}^{(27,28,29)}$.
En líneas generales, los resultados presentados indican que las mujeres no comprenden el resultado recibido y que esta falta de comprensión tiene un efecto negativo en sus vidas, que va desde una percepción internalizada del estigma, discusiones y separaciones de sus parejas, hasta la vivencia de una ruptura biográfica. Estos hallazgos coinciden con investigaciones que indican que la recepción de un resultado positivo de test de $\mathrm{VPH}$ y/o de citología anormal es un acontecimiento que irrumpe en la vida de las mujeres, generándoles un estado de gran ambigüedad, impacta en sus subjetividades y produce cambios en sus vidas cotidianas s $^{(3,8,9,17,18,21)}$.

En nuestro corpus, las percepciones que movilizan sentimientos negativos tienen que ver con una asociación acentuada entre el VPH y el cáncer, así como con una gran preocupación por la transmisión sexual del virus. En esta línea, diversas investigaciones encuentran que las mujeres con resultado de $\mathrm{VPH}+$ y/o de citología anormal atribuyen una gravedad desmedida al diagnóstico y lo asocian a un resultado de cáncer ${ }^{(7,13,30)}$. Con respecto al carácter de transmisión sexual, nuestros hallazgos coinciden con estudios que indican que este aspecto es central para las mujeres $\mathrm{VPH}+$, ya que moviliza percepciones sociales ligadas al estigma, la vergüenza y la infidelidad $^{(7,10,18,31,32)}$. Los sentimientos negativos relacionados con este aspecto se vinculan con percepciones sociales tradicionales sobre femineidad, masculinidad y fidelidad, tal como lo indica una investigación sobre estigma y VPH Ilevada a cabo en México ${ }^{(31)}$. Estas percepciones remiten a una doble moral sexual, a partir de la cual se establecen códigos morales diferenciados por género, que subordinan la actividad sexual femenina al compromiso afectivo y al amor de pareja; mientras que, en los hombres, se habilita la actividad sexual no subordinada al matrimonio o al noviazgo. Si bien este modelo de domesticidad es cuestionado como norma social a partir de la década de 1970, sus valores, como muestran los testimonios, en cierta medida y no sin contradicciones, permanecen vigentes, al igual que en otros grupos sociales ${ }^{(33)}$. Las percepciones sobre el diagnóstico también se vinculan con 
miradas sobre el sistema de salud y los estudios ginecológicos de prevención. Es el caso de las mujeres que subestiman el resultado, quienes tienden a desconfiar del diagnóstico, así como de las intervenciones médicas y de las y los profesionales de la salud. A su vez, aquellas que expresan confusión plantean dificultades a la hora de hacer preguntas durante la consulta médica. Una investigación llevada a cabo en México encuentra que el derecho a la información de mujeres que participan de programas de detección de cáncer de cuello de útero y cáncer de mama, se obstaculiza e invisibiliza en el campo médico debido a prácticas de subordinación de las mujeres usuarias $^{(34)}$. Así, la falta de comprensión de las mujeres evidenciada por nuestro estudio se puede leer como una vulneración de derechos, en el marco de relaciones de poder asimétricas entre médicos y médicas y las pacientes, dado que el resultado de esa interacción no resulta en información accesible y entendible para ellas, que permita garantizar la continuidad del proceso de atención ${ }^{(35,36)}$. Nuestros hallazgos sugieren que es necesario desplegar estrategias -capacitaciones, intervenciones interdisciplinarias, entre otraspara procurar modificar habitus profesionales internalizados. En términos de Roberto Castro, las y los profesionales de la medicina incorporan en forma de habitus las relaciones de poder del campo médico, lo que se traduce en un "habitus médico autoritario" que vulnera los derechos de las pacientes ${ }^{(37)}$. El concepto de habitus remite a la interiorización de estructuras objetivas que, a su vez, permiten la reproducción de esas estructuras ${ }^{(38)}$. Este habitus se construye en la formación médica en las universidades y hospitales de enseñanza, con una estructura rígida, jerárquica y verticalista del campo médico y sostiene una visión patriarcal de las usuarias, que no son reconocidas como sujetos de derechos ${ }^{(37,39)}$. Modificar estos mecanismos es central, para poder desplegar mecanismos de entrega de resultados más centrados en las pacientes y en sus necesidades particulares. Los procesos de entrega y de educación para la salud o consejería, en los casos en los que sea posible, deben apuntar tanto a disminuir los efectos en la salud psicosocial de las mujeres diagnosticadas como a garantizar la adherencia, con un foco puesto en la escucha activa y en brindar información diferencial según la comprensión y las necesidades particulares de cada mujer.

Con respecto a la mirada sobre sus cuerpos, las mujeres que sobreestiman el resultado o lo confunden ven modificada esta percepción al interpretar distintos síntomas físicos a partir del diagnóstico recibido. Una investigación llevada a cabo en Suecia describe que mujeres que continúan el proceso de seguimiento posterior a un resultado de Pap anormal reconceptualizan la mirada sobre sus cuerpos en tanto comienzan a "escucharlo" y a prestar atención a sus experiencias corporeizadas $^{(40)}$. En nuestro análisis, las mujeres no solamente cambian sus sensaciones y percepciones físicas, sino que confunden síntomas, al interpretar otros problemas ginecológicos, como una menstruación abundante, con relación al resultado recibido. A su vez, las mujeres que sobreestiman el resultado, dan cuenta de cómo se entrelazan las sensaciones y dolores físicos y emocionales, con frases como "me duele psicológicamente". Sin embargo, una investigación llevada a cabo en México sobre las percepciones de parteras y promotoras de salud, encuentra que dichas agentes vislumbran en las mujeres pacientes un cuerpo fragmentado, física y emocionalmente ${ }^{(41)}$. Esta mirada dicotómica entre un cuerpo biomédico y uno emocional puede estar muy presente en las instituciones y agentes de salud, por lo que es fundamental desarrollar investigaciones que integren el componente psicosocial a las experiencias corporeizadas de las mujeres, así como fomentar estrategias integrales de atención.

Otro aporte particular de nuestra investigación es el análisis de los modos de comprender el resultado de un $\mathrm{VPH}+$ en función del resultado del Pap. Las mujeres que tienen resultados normales de Pap coinciden con aquellas que tienden a subestimar el resultado mientras que, aquellas que tienen resultados anormales, particularmente lesiones de alto grado, tienden a sobrestimarlo. Esto nos permite reflexionar sobre la necesidad de continuar las investigaciones para generar 
recomendaciones específicas para mujeres $\mathrm{VPH}+$ con Pap normal. Al tratarse de un diagnóstico relativamente nuevo y de mayor ambigüedad, puede generar dificultades adicionales de comprensión. Además, las mujeres $\mathrm{VPH}+$ con Pap normal son un grupo escasamente estudiado que tiene un riesgo elevado de desarrollar lesiones de alto grado ${ }^{(42,43)}$ y presenta muy bajos niveles de adherencia, según indica una investigación llevada a cabo en Argentina $^{(44)}$.

Si bien tenemos en cuenta las diferencias entre mujeres $\mathrm{VPH}+$ con Pap normal y anormal, la inclusión de mujeres con diferentes recorridos de atención puede ser una limitación del estudio. Es importante tener en cuenta que las entrevistas se realizaron luego de dos años de la toma del test, lo cual puede modificar las experiencias de las mujeres con relación al proceso de prevención y tratamiento y, por lo tanto, su percepción sobre el diagnóstico previo. Otra limitación del estudio radica en la exclusión de los procesos de entrega de resultados como foco de investigación. Sería importante estudiar las modalidades de comunicación entre profesionales y usuarias, a los fines de desarrollar estrategias comunicativas acordes a cada contexto.

\section{CONCLUSIONES}

Las mujeres entrevistadas que recibieron un resultado positivo de test de $\mathrm{VPH}$, junto con un Pap normal o anormal, en la provincia de Jujuy durante el año 2013, no comprenden, en general, la ambigüedad de un resultado asintomático con indicación de seguimiento. Las entrevistadas pueden confundir el significado del diagnóstico, o subestimar o sobrestimar su gravedad. Sus percepciones varían en función de si tienen un resultado normal o anormal de Pap, es decir, si poseen o no lesiones en el cuello del útero, pero también de su interpretación del resultado asociándolo al cáncer y al estigma de una infección de transmisión sexual, así como de sus miradas sobre el sistema de salud. La falta de comprensión moviliza sentimientos negativos, irrumpe en la vida de las mujeres y tiene consecuencias que pueden implicar la percepción de una ruptura biográfica en sus vidas. Estas situaciones dan cuenta, entre otros aspectos, de las limitaciones de las instituciones de salud para responder al derecho a la información de las mujeres usuarias, que quedan relegadas a una posición subordinada dentro del campo médico.

Los resultados de esta investigación sugieren que es necesario diversificar estrategias para mejorar las entregas de resultados y los distintos soportes de comunicación orientados a la comprensión y difusión de información sobre un resultado positivo del test de $\mathrm{VPH}$. Encontramos fundamental que estas herramientas pongan el foco en las necesidades específicas de las mujeres en función de sus marcos normativos previos, así como de sus necesidades particulares de información y contención. Estas intervenciones se deben orientar a constituir como un "problema digno de atención" ${ }^{\prime(39)}$ dentro del campo médico, el derecho a la información de las mujeres usuarias. No se trata solamente de brindar información o de explicar el resultado, sino de fomentar mecanismos de diálogo y escucha activa en la consulta, orientados a la comprensión del diagnóstico recibido y del proceso de atención posterior, a partir de las percepciones y vivencias de las propias mujeres. Este horizonte responde al objetivo de salud pública de mejorar la adherencia de las mujeres al proceso de prevención del cáncer de cuello de útero, pero también a una mirada ética de derechos humanos que se proponga incorporar los proyectos y experiencias de vida, y los derechos de las personas, en la planificación de los servicios y la prevención en salud.

\section{CONFLICTO DE INTERESES}

No hay conflicto de intereses vinculado a la publicación de este artículo.

\section{AGRADECIMIENTOS}

Agradecemos a Alicia Campanera por su compromiso y apoyo durante el trabajo de campo. Al Consejo Nacional 
de Investigaciones Científicas y Técnicas (CONICET) por la beca de extensión de doctorado 2017-2019 a Lucila Szwarc por el proyecto "Entrega de resultados de un test de $\mathrm{VPH}+$ y posterior proceso de seguimiento y tratamiento: las experiencias de las mujeres y la mirada de los profesionales en la provincia de Jujuy". Agradecemos también a los y las profesionales y agentes sanitarios que nos recibieron en los centros de salud y hospitales durante el trabajo de campo, colaboraron en las entrevistas y en el contacto con las mujeres a entrevistar. Agradecemos especialmente a las mujeres que brindaron sus valiosos testimonios sobre temas íntimos de sus vidas.

\section{REFERENCIAS BIBLIOGRÁFICAS}

1. Almonte M, Murillo R, Sánchez GI, Jerónimo J, Salmerón J, Ferreccio C, Lazcano-Ponce $\mathrm{E}$, Herrero $\mathrm{R}$. Nuevos paradigmas y desafíos en la prevención y control del cáncer de cuello uterino en América Latina. Salud Pública de México. 2010;52(6):544-559.

2. Arrossi S. Prevención del cáncer cervicouterino: recomendaciones para el tamizaje, seguimiento y tratamiento de mujeres en el marco de programas de tamizaje basados en el test de VPH: actualización 2015. Ciudad Autónoma de Buenos Aires: Instituto Nacional del Cáncer; 2015

3. Karasz A, McKee MD, Roybal K. Women's experiences of abnormal cervical cytology: Illness representations, care processes, and outcomes. Annals of Family Medicine. 2003;1(4):196-202. doi: 10.1370/afm.31.

4. Forss A, Tishelman C, Widmark C, Sachs L. Women's experiences of cervical cellular changes: an unintentional transition from health to liminality? Sociology of Health \& Illness. 2004;26(3):306-325.

5. Sánchez Antelo V, Kohler RE, Szwarc L, Paolino M, Kasisomayajula V, Arrossi S. Knowledge and perceptions regarding triage among human Papillomavirus-tested women: A qualitative study of perspectives of low-income women in Argentina. Women's Health. 2020;16:174550652097601. doi: 10.1177/1745506520976011.

6. Rajaram SS, Hill J, Rave C, Crabtree BF. A biographical disruption: The case of an abnormal pap smear. Health Care for Women International. 1997;18(6):521531. doi: 10.1080/07399339709516308.

7. Rask M, Swahnberg K, Lindell G, Oscarsson M. Women's experiences of abnormal Pap smear results A qualitative study. Sexual \& Reproductive Healthcare. 2017;12:3-8. doi: 10.1080/0167482X.2019.1657090.

8. Leite V, Santos BD, Pereira MG. Psychosocial impact of human papillomavirus on women's sexual dissatisfaction and quality of life. Journal of Psychosomatic Obstetrics and Gynaecology. 2019;40(3):232-238. doi: 10.1080/0167482X.2018.1470164.

9. Arrossi S, Almonte $M$, Herrero R, Gago J, Sánchez Antelo V, Szwarc L, Thouyarete L, Paolino M, Wiesnerf C. Psycho-social impact of positive human papillomavirus testing in Jujuy, Argentina results from the Psycho-Estampa study. Preventive Medicine Reports. 2020;18:101070. doi: 10.1016/j.pmedr.2020.101070.
10. Waller J, Marlow LAV, Wardle J. The association between knowledge of HPV and feelings of stigma, shame and anxiety. Sexually Transmitted Infections. 2007;83(2):155-159. doi: 10.1136/sti.2006.023333.

11. León-Maldonado L, Allen-Leigh B, Lazcano-Ponce E. Consejería en la detección de VPH como prueba de tamizaje de cáncer cervical: un estudio cualitativo sobre necesidades de mujeres de Michoacán, México. Salud Pública de México. 2014;56(5):519-527.

12. Verhoeven V, Baay MFD, Baay PE, Lardon F, Van Royen P, Vermorken JB. Everything you always wanted to know about HPV (but could not ask your doctor). Patient Education and Counseling. 2010;81(1):101-105. doi: 10.1016/j.pec.2009.12.006.

13.MarvánML,EhrenzweigY, Catillo-López RL.Fatalisticbeliefs and cervical cancer screening among Mexican women. Health Care for Women International. 2016;37(1):140154. doi: 10.1080/07399332.2014.959169.

14. Zamberlin N, Thouyaret L, Arrossi S. Lo que piensan las mujeres: conocimientos y percepciones sobre cáncer de cuello de útero y realización de PAP. Buenos Aires: Organización Panamericana de la Salud; 2011.

15. Horvath JDC, Kops NL, Caierão J, Bessel M, Hohenberger G, Wendland EM. Human papillomavirus knowledge, beliefs, and behaviors: A questionnaire adaptation. European Journal of Obstetrics \& Gynecology and Reproductive Biology. 2018;230:103-108. doi: 10.1016/j.ejogrb.2018.09.023.

16. Hounsgaard L, Petersen LK, Pedersen BD. Facing possible illness detected through screening-experiences of healthy women with pathological cervical smears. European Journal of Oncology Nursing. 2007;11(5):417423. doi: 10.1016/j.ejon.2007.04.005.

17. Castro Vásquez MC, Arellano Gálvez MC. Redes sociales de apoyo y género: vivencia de mujeres con $\mathrm{VPH}$ displasias y cáncer cervicouterino. La Ventana: Revista de Estudios de Género. 2014;5(39):208-240.

18. Monsalve-Páez S, Valderrama-Vega D, CastilloZamora MF, Guzmán-Sabogal YR, Amaya-Guío J. Experiencia de las pacientes frente a citología cérvico-vaginal reportada como ASCUS o LEI de bajo grado en dos instituciones de Bogotá (Colombia), 2014. Revista Colombiana de Obstetricia y Ginecología. 2015;66(1):14-21.

19. Minayo MCS. El desafío del conocimiento: Investigación cualitativa en salud. Buenos Aires: Lugar Editorial; 2015.

20. Jones D, Manzelli H, Pecheny M. Grounded theory: Una aplicación de la teoría fundamentada a la salud. Cinta de Moebio. 2004;(19):38-54.

21. León-Maldonado L, Wentzell E, Brown B, AllenLeigh B, Torres-lbarra L, Salmerón J, et al. Perceptions and experiences of human papillomavirus (HPV) infection and testing among low-income Mexican women. PLOS ONE. 2016;11(5):e0153367. doi: 10.1371/journal. pone.0153367. 
22. Evangelista Rodrigues D, Alves Moreira KF, Souza de Oliveira T. Barriers to prevention of cervical cancer in the city of Porto Velho, Rondônia, Brazil. Investigación y Educación en Enfermería. 2016;34(1):59-67.

23. Yunus N, Mohamed Yusoff H, Draman N. Non-Adherence to recommended Pap smear screening guidelines and its associated factors among women attending health clinic in Malaysia. Malaysian Family Physician. 2018;13(1):10-17.

24. Carricaburu D, Pierret J. Vie quotidienne et recompositions identitaires autour de la séropositivité. Paris: CERMES-ANRS; 1992.

25. Bury M. Illness narratives: fact or fiction? Sociology of Health and Illness. 2001;23(3):263-285.

26. Varaldo CN. Convivendo com a hepatite C: Manual da convivência - Experiências e Informações de um portador do virus. Rio de Janeiro: Carlos Varaldo; 2003.

27. Kavanagh AM, Broom DH. Women's understanding of abnormal cervical smear test results: a qualitative interview study. BMJ. 1997;314(7091):1388-1391.

28. Castro-Vásquez MC, Arellano-Gálvez MC. Acceso a la información de mujeres con $\mathrm{VPH}$, displasia y cáncer cervical in situ. Salud Pública de México. 2010;52(3):207-212.

29. Vamos CA, Calvo AE, Daley EM, Giuliano AR, López Castillo H. Knowledge, behavioral, and sociocultural factors related to human papillomavirus infection and cervical cancer screening among inner-city women in Panama. Journal of Community Health. 2015;40(6):10471056. doi: 10.1007/s10900-015-0030-4.

30. Perrin KKM, Daley EM, Naoom SF, Packing-Ebuen JL, Rayko HL, McFarlane M, et al. Women's reactions to HPV diagnosis: insights from in-depth interviews. Women Health. 2006;43(2):93-110. doi: 10.1300/J013v43n02_06.

31. Arellano Gálvez MC, Castro Vásquez MC. El estigma en mujeres diagnosticadas con VPH, displasia y cáncer cervicouterino en Hermosillo, Sonora. Estudios Sociales. 2013;21(42):259-278.

32. Bertram CC, Magnussen L. Informational needs and the experiences of women with abnormal Papanicolaou smears. Journal of the American Academy of Nurse Practitioners. 2008;20(9):455-462. doi: 10.1111/j.17457599.2008.00341.x.
33. Jones D. Sexualidades adolescentes: amor, placer y control en la Argentina contemporánea. Buenos Aires: CICCUS, CLACSO; 2010.

34. Castro Vásquez MC. Habitus lingüístico y derecho a la información en el campo médico. Revista mexicana de sociología. 2011;73(2):231-259.

35. Cabré Pairet M, Ortiz Gómez T. Presentación. Asclepio. 2008;60(1):9-18.

36. Valls-Llobet C. La salud bio-psico-social re-generada. Quaderns de Psicologia. 2010;12(2):175-181.

37. Castro R. Génesis y práctica del habitus médico autoritario en México. Revista Mexicana de Sociología. 2014;76(2):167-197.

38. Bourdieu P. Raisons pratiques. Paris: Éditions Points; 1994.

39. Erviti J, Sosa IA, Castro R. Simposio X: Respeto a los derechos reproductivos en las políticas de salud reproductiva. Salud Pública de México. 2007;49(Esp. 1):161-165.

40. Blomberg K, Forss A, Ternestedt B-M, Tishelman C. From 'silent' to 'heard': Professional mediation, manipulation and women's experiences of their body after an abnormal Pap smear. Social Science \& Medicine. 2009;68(3):479-486.

41. Luna Blanco M, Sánchez Ramírez G. Los segmentos del cuerpo y sus padecimientos: un análisis preliminar de los procesos salud / enfermedad ligados al VPH y $\mathrm{CaCu}$ entre las parteras y promotores de salud de Chiapas. Cuicuilco. 2014;21(60):129-146.

42. Polman NJ, Veldhuijzen NJ, Heideman DAM, Snijders PJF, Meijer CJLM, Berkhof J. HPV-positive women with normal cytology remain at increased risk of CIN3 after a negative repeat HPV test. British Journal of Cancer. 2017;117(10):1557-1561.

43. Uijterwaal MH, Polman NJ, Witte BI, Kemenade FJ van, Rijkaart D, Berkhof J, et al. Triaging HPV-positive women with normal cytology by p16/Ki-67 dual-stained cytology testing: Baseline and longitudinal data. International Journal of Cancer. 2015;136(10):2361-2368.

44. Gago J, Paolino M, Arrossi S. Factors associated with low adherence to cervical cancer follow-up retest among HPV + / cytology negative women: a study in programmatic context in a low-income population in Argentina. BMC Cancer. 2019;19(1):367. doi: 10.1186/s12885-019-5583-7. 